\title{
THE APPLICATION OF ARTIFICIAL INTELLIGENCE TO PEST RISK ANALYSIS
}

\author{
L. PEACOCK ${ }^{1}$, S.P. WORNER ${ }^{1}$ and S. SAMARASINGHE ${ }^{2}$ \\ ${ }^{1}$ Soil, Plant and Ecological Sciences Division, P.O. Box 84, Lincoln University, \\ Canterbury \\ ${ }^{2}$ Environmental Management and Design Division, P.O. Box 84, Lincoln \\ University, Canterbury \\ Corresponding author: Peacockl@lincoln.ac.nz
}

Increased transport and anthropogenic influences have enhanced the spread of invasive species such that the impact of pest invasions is seen as one of the major threats to global biodiversity. The determination of the invasibility of species is usually based on criteria involving biological and climatic parameters applied within a risk assessment framework. In addition, to this framework, some computer based systems may be used to predict whether a species will establish in any locality. These include regression models, rule based logic systems, mechanistic models and climate envelope models. However, such models are often limited in their ability to model complex, multidimensional functions. Artificial intelligence systems, such as artificial neural networks (ANN), may provide a new approach to the prediction of species invasions. Artificial neural networks have the ability to fit complex, nonlinear relationships. In this study, biological and climate data for twenty insect species that have established in New Zealand and twenty insects that are often intercepted but not established, were used to train an ANN. Artificial neural network predictions were compared with those from a conventional multivariate statistical analysis of pest establishment.

\section{USING CHEMICAL STRUCTURE TO SELECT COMPOUNDS FOR INSECT DISINFESTATION RESEARCH}

\author{
G.C. BRADFIELD, P.R. DENTENER and P.G. CONNOLLY
}
The Horticulture and Food Research Institute of New Zealand Ltd, Private Bag 92169, Auckland
Corresponding author: gbradfield@hortresearch.co.nz.

\begin{abstract}
New methods for insect disinfestation of fresh export commodities are being investigated worldwide as the fumigant methyl bromide faces increased restrictions on its use. Generally Recognized As Safe (GRAS) volatile compounds may offer alternatives to current fumigation practices. An advantage of GRAS compounds is that they may be considered as 'reduced risk' when being processed for registration. Since GRAS compounds are not commonly used as insecticides, the pesticide chemistry literature was searched for chemical groupings with potential pesticidal activity, and these were cross-referenced against the GRAS database. A range of disinfestation experiments were carried out with cineoles, propyl- and butylacetates and formates (GRAS) and several of their isomers (non-GRAS), to determine their efficacy against fifth instar Epiphyas postvittana at $20 \pm 2{ }^{\circ} \mathrm{C}$. All chemicals showed some degree of insecticidal activity. Formates were more effective than acetates and cineoles, with iso-forms being more insecticidal than their 'parent' straight chain. Results indicate that chemical structure may be a useful tool in selecting compounds for insect disinfestation.
\end{abstract}

